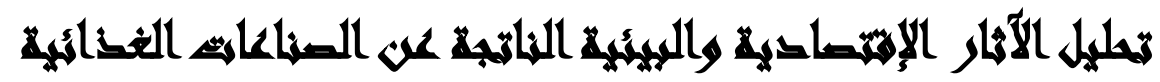

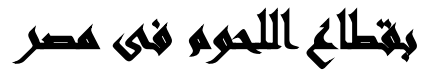

\section{$[r \leqslant]$}

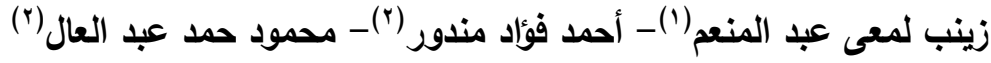

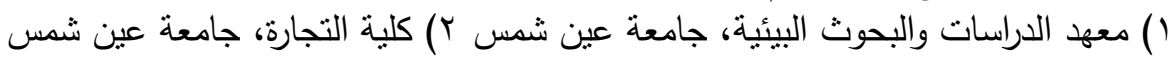

\section{المستخلتص}

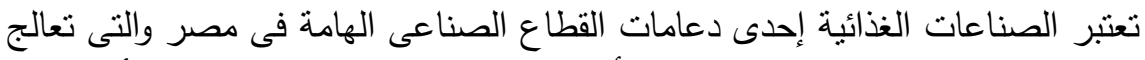

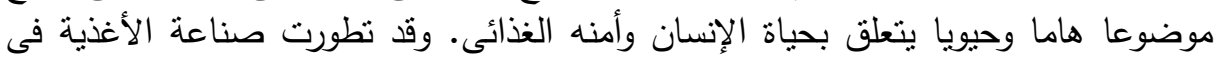

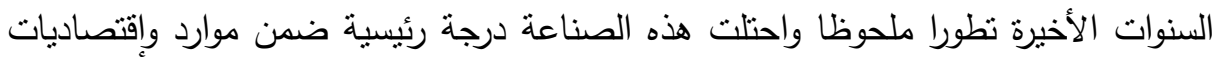

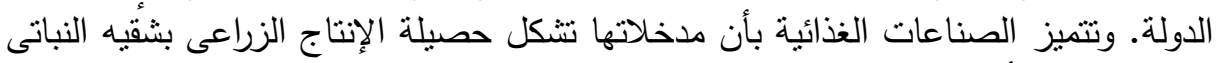

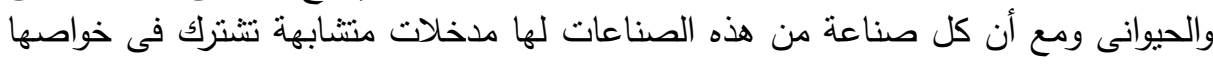

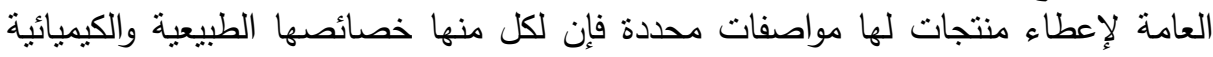

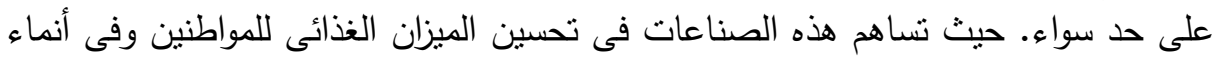

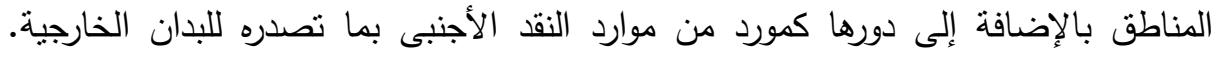

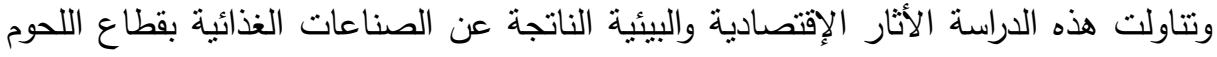

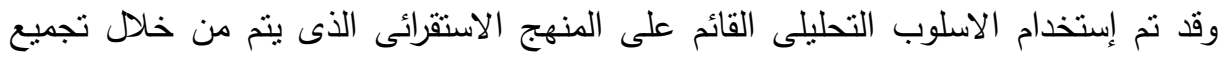

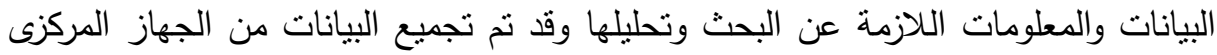

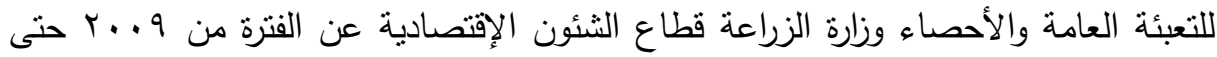

وقد أسفرت النتائج أن الصناعات الغذائية بقطاع اللحوم لها تأثثر كبير فى التتمية

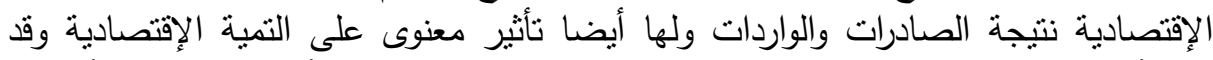

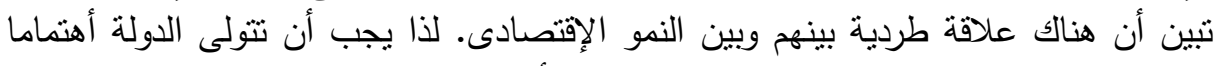

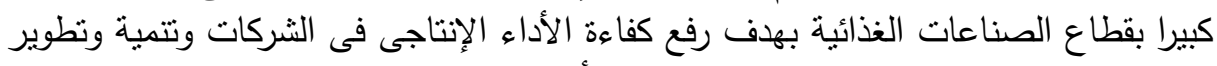

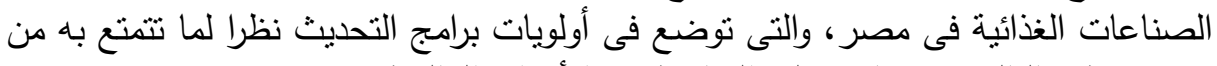

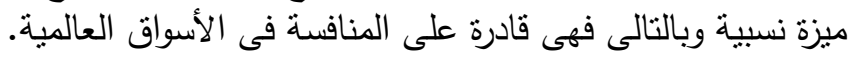




\section{هي⿻}

شهدت السنوات الأخيرة للألفية الثانية تقدما هائلا وثورات تكنولوجية وصناعة مذهلة حتى أطلق على هذا القرن (قرن الثورات العلية وقرن التكنولوجيا والجينات) كما حدث تداخل

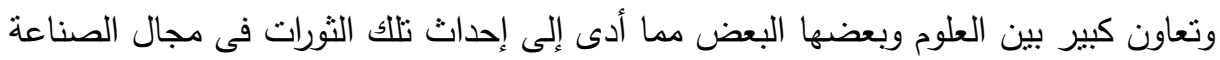

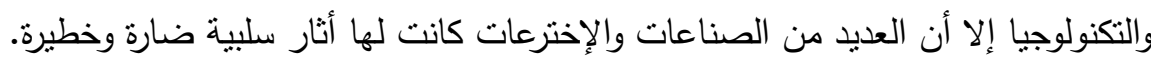
ولقد أحدث التقام العلمى فى مجال الصناعة والإنتاج الغذائى ثورة حقيقة من حيث الكم الكي

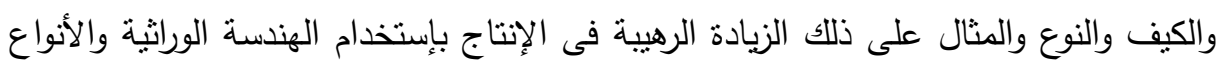
العديدة من المنتجات الغذائية المستحدثة ذات الأصل الحيوانى أو النباتى وهكذا.

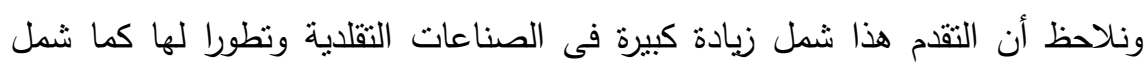

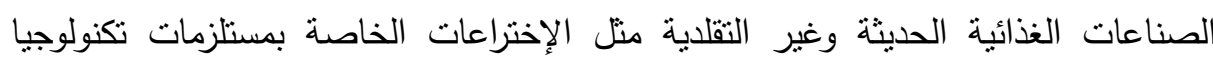
الصناعات الغذائية وطرق الإعداد والتجهيز والنقل والتخزين والتوزيع وغيرها.

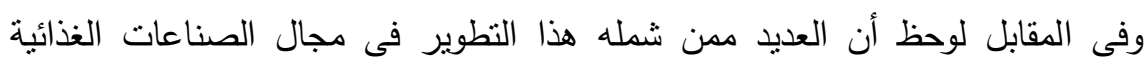

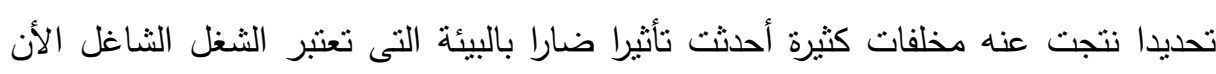
لكثير من العلماء والمتخصصين والمهتمة بإدارة الأزمات. وفى بحثنا هذا سوف نركز على الصناعات الغذائية واللحوم كنموذجا ما حدث لها من

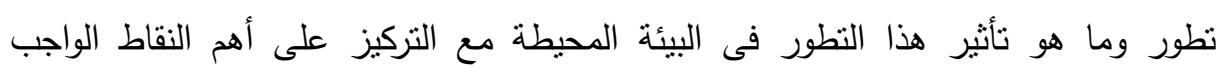

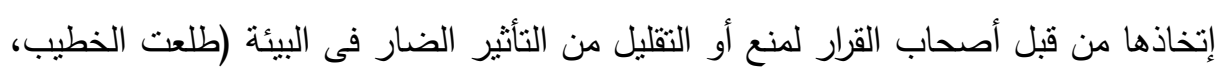

$$
\cdot(r+. \wedge
$$

ولقد شهدت مراحل إنتاج وتصنيع المواد الغذائية فى العقد الأخير تطورا ملموسا وزادت

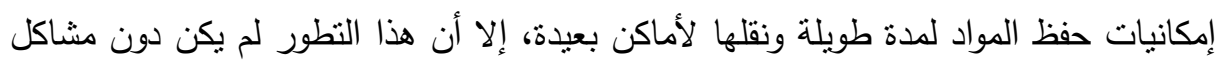

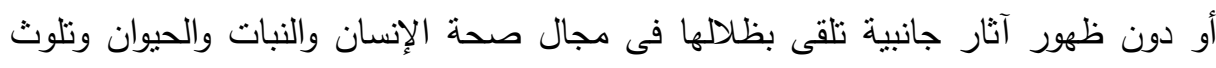

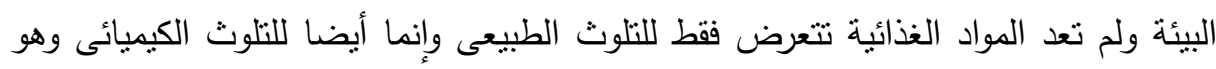

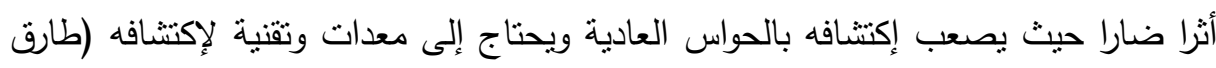

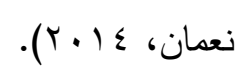




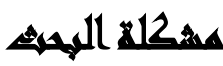

يعتبر قطاع الصناعات الغذائية من أهم القطاعات فى مصر حيث أنه يلعب دورا هاما

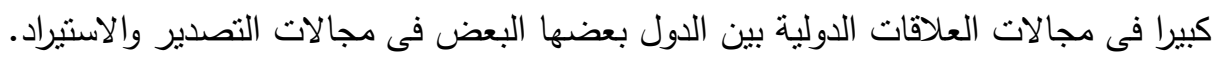

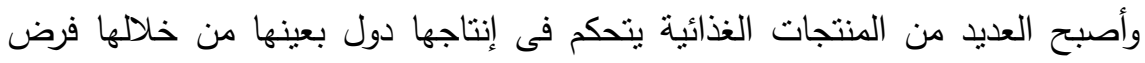

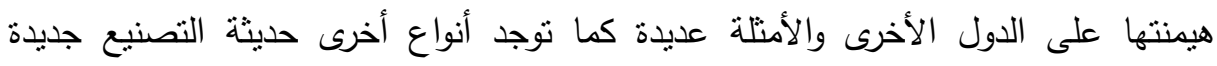

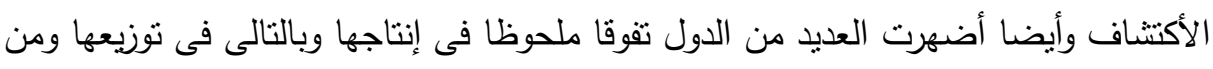

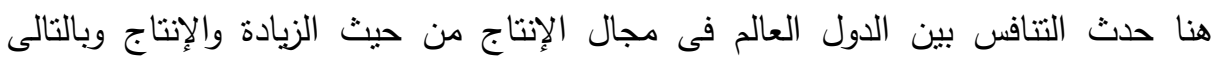
الإكثناء الذاتى ومن ثم التصدير وإدخال أصناف جديدة ومصانع جديدة.

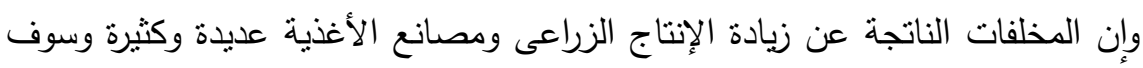

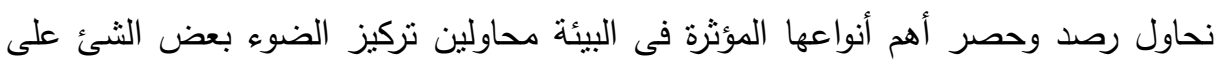

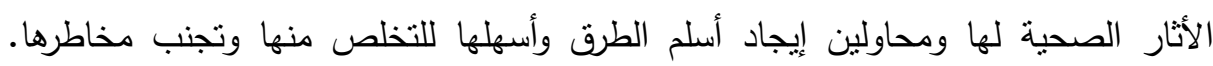

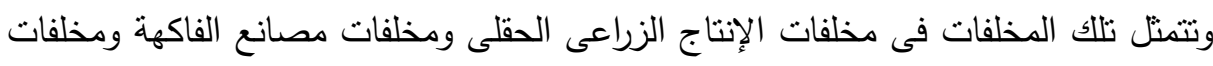

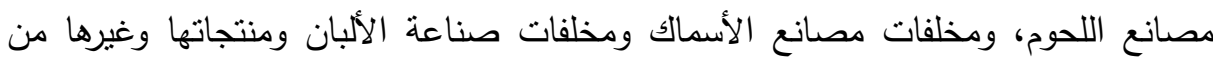

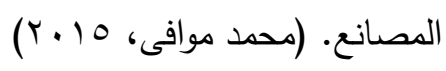

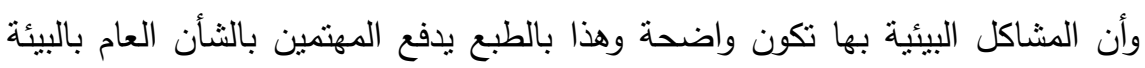

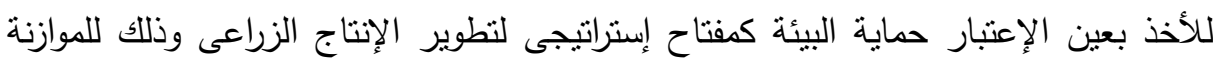

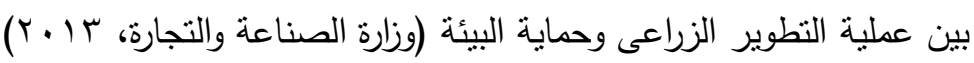

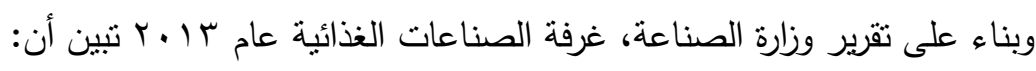

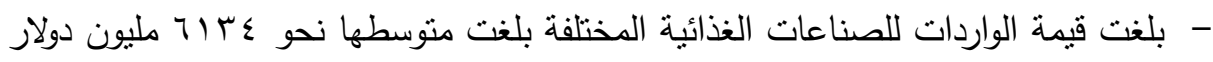

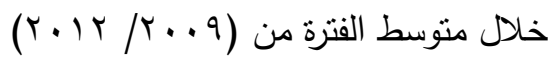

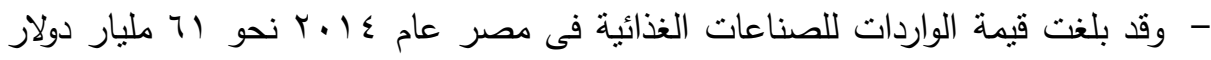
بقيمة 1/1 \% من إجمالى الواردات المصرية (1) 
جدول(1): نسبة الصناعات الغذائية من إجمالى الواردات

\begin{tabular}{|c|c|c|}
\hline النسبة المئوية & عام & المسلسل \\
\hline$\% 9,0$ & $r \ldots q$ & $\overline{1}$ \\
\hline$\% 1,, 0$ & $r .1$. & r \\
\hline$\% \backslash 1,1$ & $T .11$ & $r$ \\
\hline$\% \backslash$ \%,० & $T . / T$ & $\xi$ \\
\hline
\end{tabular}

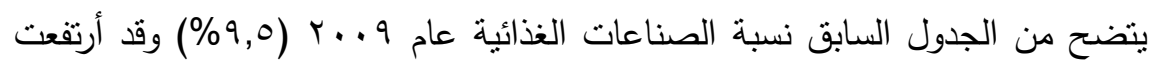

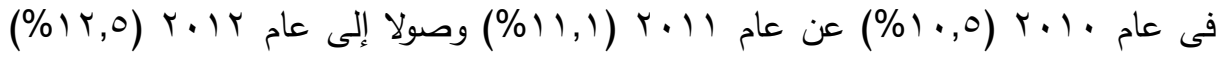

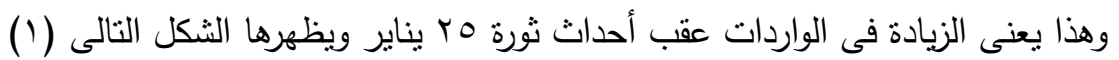

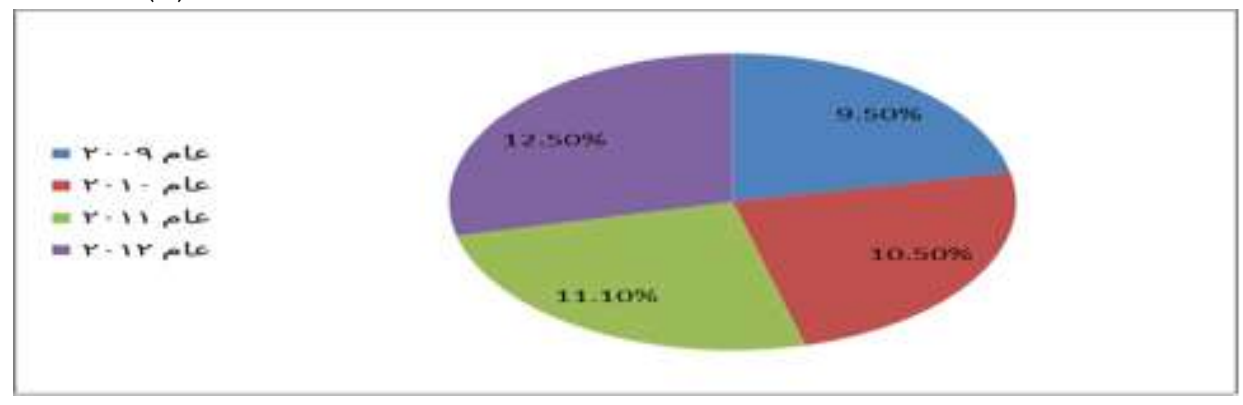

شكل(1)

وقد بلغت قيمة الصادرات للصناعات الغذائية المختلفة بلغت منوسطها نحو ع ro

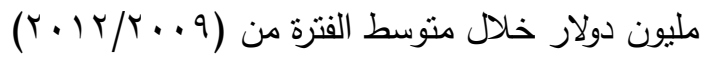
جدول(r): نسبة الصناعات الغذائية من إجمالى الصادرات

\begin{tabular}{|c|c|c|}
\hline الصادرات & عام & المسلسل \\
\hline$\% \backslash, \vee \vee$ & $r \ldots q$ & 1 \\
\hline$\% \backslash r, 1$ & $r .1$. & Y \\
\hline$\% \backslash r, \wedge$ & 4.11 & $r$ \\
\hline$\% \backslash r, \varepsilon$ & $r . I T$ & $\varepsilon$ \\
\hline
\end{tabular}

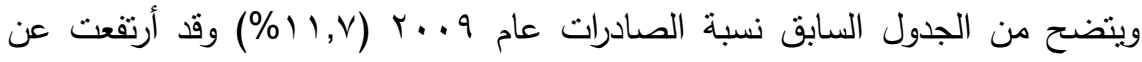

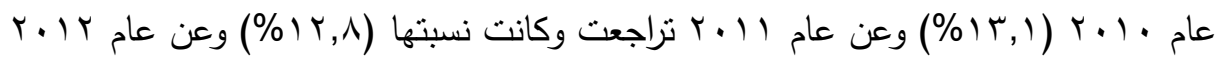

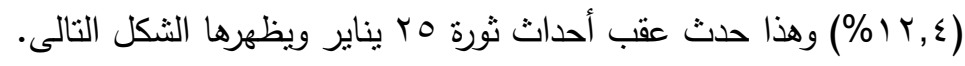


مجلة العلوم البيئية

معهد الدراسات والبحوث البيئية - جامعة عين شمس لئس

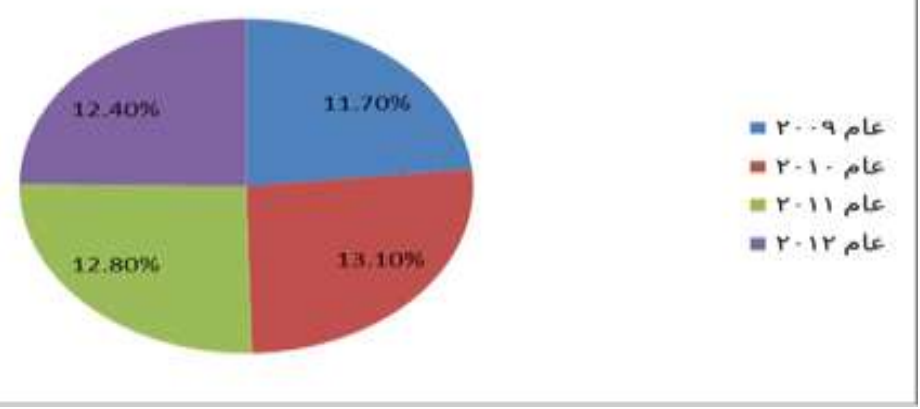

شكل(r)

وإن الواردات المصرية بلغت 70 مليار دولار حيث بلغ حجم الصادرات 0،1، مليار

وقد بلغت فجوة بين الصادرات والوردات المصرية للصناعات الغذائية أكثر من هـ؟

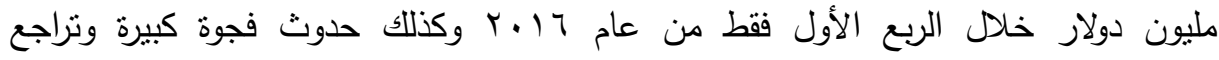

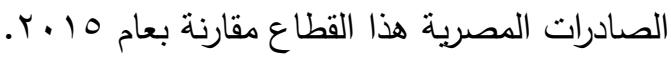
وإن إجمالى الصادرات المصرية من الصناعات الغذائية خلال الربع الأول من العام بعام

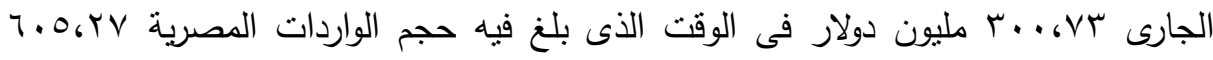

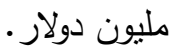

مرجع وزارة الصناعة والتجارة الهيئة العامة على الصادرات والواردات غرفة الصناعات

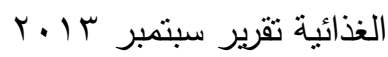

\section{أسيكلة المهAه}

هل تؤثز الصناعات الغذائية فى التتمية الإقتصادية؟

\section{أهما اهخ المهنه}

• دراسة أهية قطاع الصناعات الغذائية فى دعم الإقتصاد المصرى مع توضيح دور الدولة فى دعم هذا القطاع.

• إستتناج التحديات التى تواجة الصناعات الغذائية بقطاع اللحوم فى مصر .

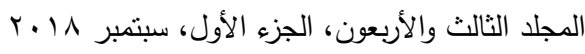




\section{هونه}

هنالك علاقة طردية بين الصناعات الغذائية وقطاع اللحوم على النمو الإقتصادى المصرى.

\section{متغنيرايت المبهث}

يبنى البحث الحالى نموذجا أفتراضيا بعبر عن التأثنر المنطقى بين المتغيرات المستقلة

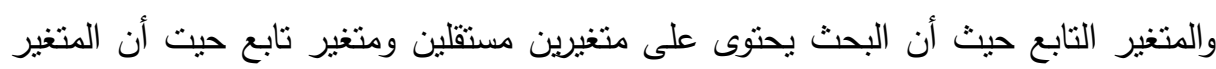

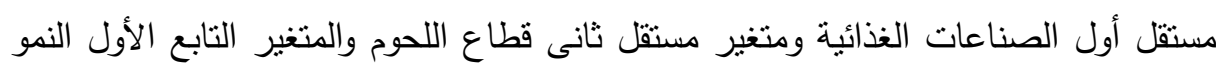

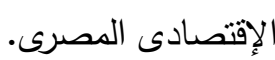

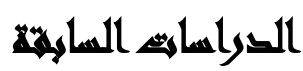

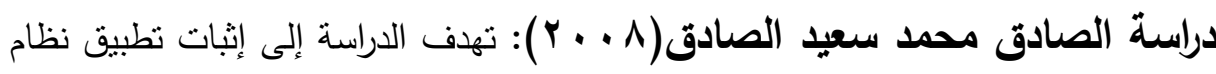
تحليل المخاطر ونقاط التحكم الحرجة فى الصناعات الغذائية للخضر والفاكهة يؤدى إلى لى إلى الحصول على منتجات غذائية آمنة صحيا وغير ضارة بالإنسان والبيئة وله عوائد إقتصادية تتمنل فى تخفيض تكاليف الإنتاج وزيادة الصادرات. وأسفرت النتائج عن أهمية الصناعات الغذائية للخضر والفاكهة فى الإقتصاد القومى فئى حيث نعتبر فرعا أساسيا من فروع النشاط الصناعى فهى تلعب دورا هاما فى تحسين الميزان

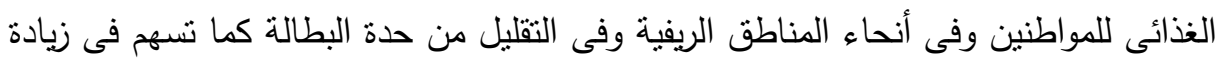

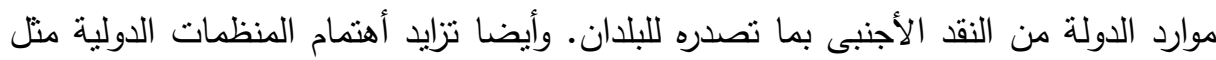
منظمة الصحة العالمية ومنظمة الأغذية والزراعة والكودكس لجنة دستور الأغذية ومنظمة الهنة

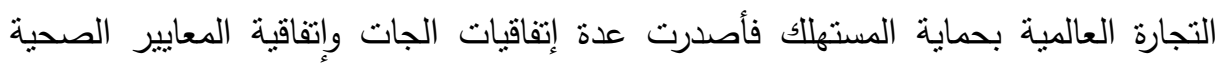
والصحة النباتية وإتفاقية الحواجز الفنية فى التجارة الدولية.

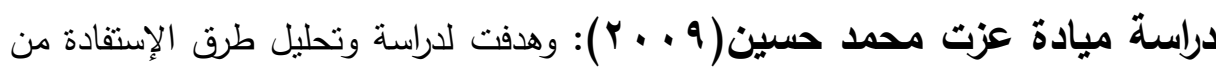
مخلفات بعض الصناعات الغذائية وصناعة العصائر والمركزات. وتحديد العوائد البيئية والإقتصادية المحققة من عمليات تدوير المخلفات. 
وأسفرت النتائج أن عملية تدوير وإسترجاع مخلفات تصنيع الفاكهة تقوم على الإستفادة من هذه المخلفات كمواد خام ثانوية ينتج عنها منتجات جديدة، حيث يمكن إستخدام هذه المخلفات فى إنتاج أعلاف غير تقليدية لتغذية الحيونات وسد النقص فى الأعلاف المركزة

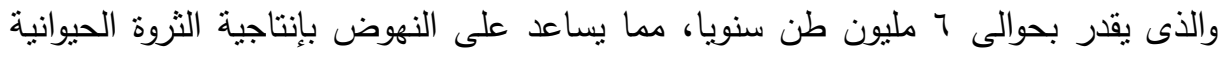
وتحقيق الإكتفاء الذاتى من المنتجات الحيوانية. كما يمكن إستخدام مخلفات تصنيع الفاكهة كمواد خام ثانوية لإنتاج سماد عضوى صناعى يحسن خصوبة التربة وذلك لإحتواء هذه المخلفات على مواد عضوية وعناصر سمادية عالية جدا. تستخدم مخلفات تصنيع الفاكهة الفاكهة فى تدعيم بعض الصناعات الهامه مثل صناعة الدواء حيث يحتوى قشور البرتقال على مادة البكتين التى تخفض نسبة الكولسترول فى الدم وأيضا مادة التيوماتوديز التى تمنع من تجلط الدم على هدئ هدار الأوعية الدموية.

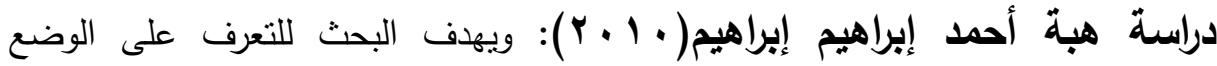
الإنتاجى الراهن، والمتغيرات الإقتصادية المؤثرة على إستجابة المزارع نحو التوسع فى المساحة

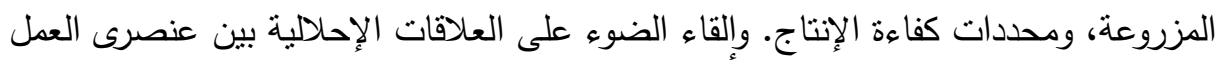
ورأس المال الخاصة بمحصولى البطاطس والطماطم فى مصر .

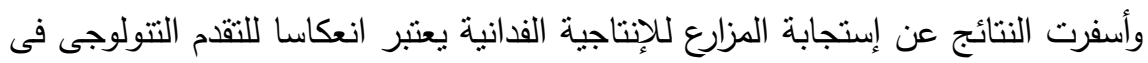
زراعة محصولى البطاطس والطماطم ولذلك توصى الدراسة بضرورة تفعيل دور الإرشاد الزراعى والحملات القومية للنهوض بإنتاجية محصولى البطاطس والطماطم. هناك تغير تكنولوجى فى إنتاج محصولى البطاطس والطماطم على مستوى العروات

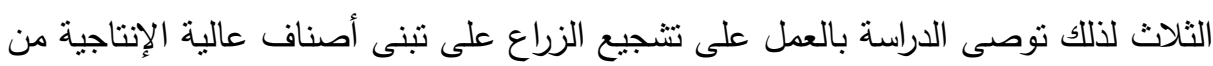
البطاطس والطماطم. دراسة محمد رمضان عبدالرازق( • ( • ؟): هدف البحث لبيان دور علم المحاسبة فى قياس التكاليف وقياس العائد البيئى من إعادة إستخدام المياه وذلك من خلال البيانات والمعلومات التى يوفرها علم المحاسبة من خلال أساليب العرض والتحليل للقوائم المالية بدقة والتى تميز بها علم المحاسبة لحل مشكلة البيئة، مما يجعل علم المحاسبة نافعا للمجتمع ككل

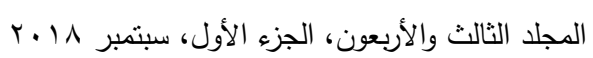


وليس للمشروعات الصناعية فقط. وتوضيح كيفية تقدير التكاليف الخاصة بإعادة إستخدام المخلفات الناتجة عن الصناعة ومنها المياه، مما يؤدى إلى تحقيق وفورات إجنماعية وإقتصادية فى حالة إعادة إستخدام المياة. مثلا يتحقق وفورات ناتجة من تخفيض كميات المياه المياه التى تستخدم فى الصناعة وبالتالى تتوفر لإستخدامها فى مجالات أخرى فى المجتمع.

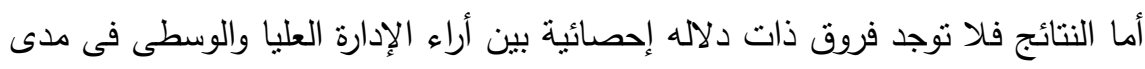

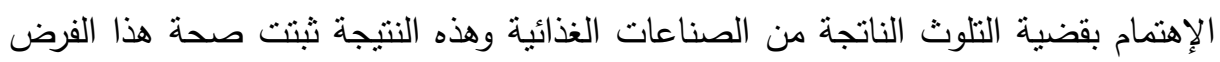
من الدراسة. كما أن هناك إرتفاع فى إهنمام إدارة شركات الصناعات الغذائية بعمل تحديث للسجل

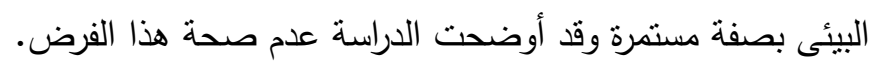
دراسة طارق نعمان إبراهيم(ع 1 ـ ب): يهدف البحث لدراسة ماهية نظم الإدارة البيئية. ودراسة المعوقات البيئية التى نواجه الصادرات المصرية عند نفاذها للأسواق الخارجية ومنها الإتحاد الأوربى والدول العربية. والمعاونة فى حماية البيئة من الأخطار من خلال نظم الإدارة

وأوضحت النتائج الأهمية البالغة لتحديث الصناعات المصرية لتلائم مع الإتجاهات

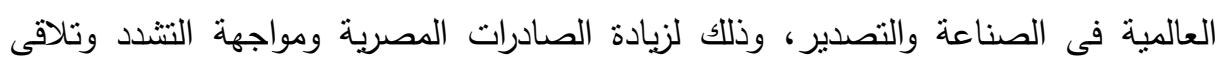

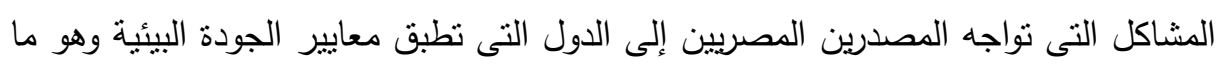

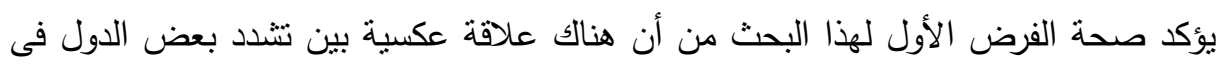
تطبيق معايير الجودة وزيادة الصادرات المصرية. كما اتضح من خلال البحث أهمية مطابقة الصناعات الغذائية المصرية لمعايير الجودة البيئية، مع ضرورة الأخذ بعمليات التحسين المستمر للقدرات الفنية للمنتجين، والمصدرين

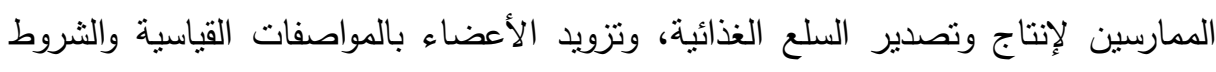
الصحية التى تضعها الدول المستوردة عند إستيراد السلع والمنتجات الغذائية، وهو مايؤكد صحة الفرض الثانى لهذا البحث من أن هناك علاقة عكسية بين رفض الدول الأجنبية للصادرات المصرية وبين حجم الصادرات المصرية. 


\section{الإطار اللنظيه}

مفاهيم وأنواع الصناعات الغذائية وقطاع اللحوم: مفهوم علم الصناعات الغذائية: عبارة عن المفاهيم النظرية والتطبيقات العلمية التى تبحث جميع الإعتبارات المتعلقة لاغذاء فى مجالات إنتاجية وتخزينة وتسويقة وتوزيعة وإستهلاكه فى إنى مراحل نهائية وأوضح هذا التعريف عام وشامل فهو يشمل نطبيق المبادئ النظرية والعملية على الغذاء تحت مراحل متعددة تختلف ظروف إحداها عن الأخرى فالظروف التى يتعرض لهابل لها الغذاء أثناء معاملات التصنييع تختلف عن ظروف التسويق والتوزيع والإستهلاك وقد حد هذا التعريف بعض المتخصصين فى حقل التصنيع الغذائى، بينما حدده البعض الآخر بأنه

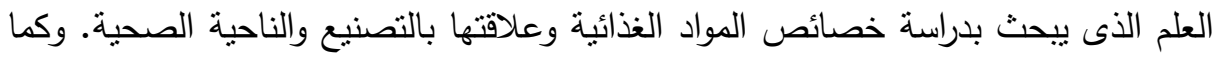
هو واضح إن هذا التعريف الأخير يكون محددا جدا إذا لم يؤخذ بنظر الإعتبار علاقة صفات الغذاء بالعوامل المؤثرة فى إنتاج المواد الخام ككمية الأمطار المتساقطة ونوع التربة ودرجة خصوبتها والصفات الوراثية للحيوانات والنباتات وطرق جني وحصاد المحاصيل الغذائية وذبح

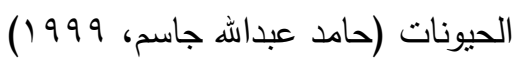
تقسيم الصناعات الغذائية: يمكن تقسيم الصناعات الغذائية وفقاً لثلاثة أسس: أولاً: طبقاً للنشاط الإقتصادى: وتقسم طبقا" لهذا الأساس إلى ثلاثة أنشطة:

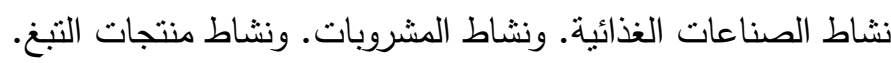
ثانياً: طبقاً لنوع المادة المحفوظة: وتقسم إلى: صناعة السكر . صناعة الزيوت. صناعة صناعة اللحوم. صناعة الأسماك. صناعة حفظ وتجميد الخضر والفاكهة. ثالثاً: طقاً لطريقة الحفظ المستخدمة: حيث تشترك مواد غذائية مختلفة تحت طريقة حفظ ونط واحدة مثل: طريقة التجفيف؛ التجميد؛ التعليب؛ التخليل؛ العصائر ؛ المركزات. كما يمكن تقسيم الصناعات الغذائية إلى نوعين هما:.

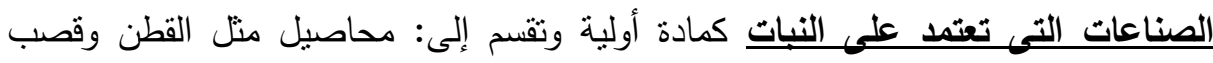
السكر والأرز والذرة. محاصيل بستانية مثل نباتات الخضر والطماطم والفاكهة. محاصيل أخرى منل الثاى والبن والتوابل والزهور والأعشاب.

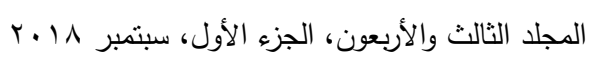


الصناعات الغذائية التى تعتمد على الحيون ويمكن تقسيمها إلى: منتجات الحيوان الزراعى

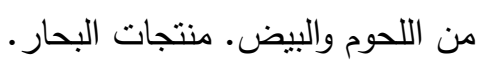

كما توجد بعض الصناعات التى تعتمد على مصادر أخرى منل المشروبات الغازية

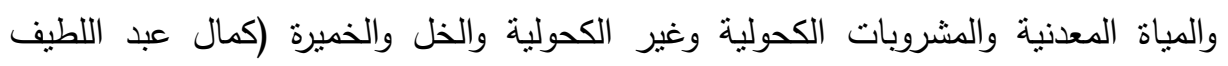

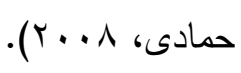

أهمية الصناعات الغذائية: إن الصناعات الغذائية صناعة حيوية مهمة تلعب دورا مهما فى الإقتصاد الوطنى للبلاد ويمكن توضيح أهيتها بالنقاط التالية:

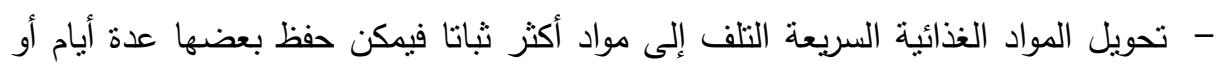
أسابيع والبعض الأخر لبضعة شهور أولفترة سنوات حسب طريقة الحفظ المتبعة. ويمكن

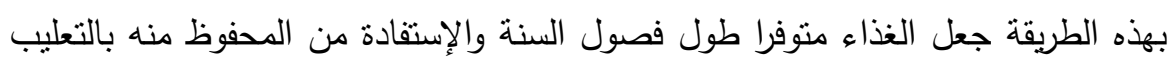
أو التجفيف أو التجمد فى مواسم وداءة الإنتاج بسبب حصول جفاف أو سقوط جليد أو أو

تعرض المحاصيل لآفات زراعية تقضى عليه.

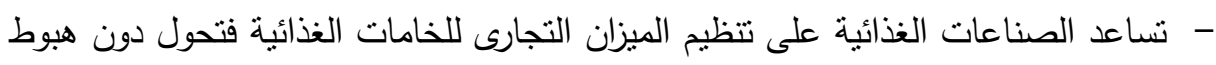

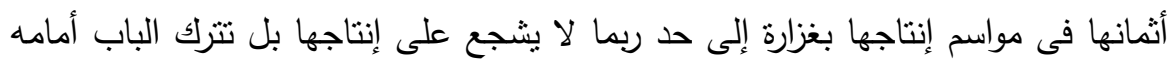

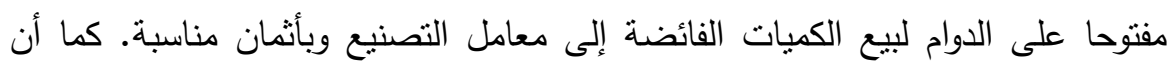

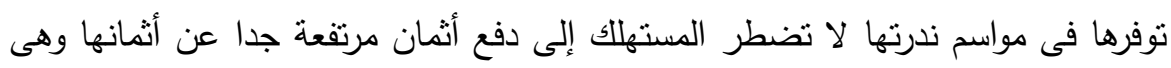

$$
\text { طازجة. }
$$

- تعمل بعض طرق الحفظ كالتجفيف مثنا على تقليل وزن الغذاء وحجمه مما يسهل ويقلل نفقات شحنه إلى مسافات بعيدة ولهذا فائدة فى نقل الغذاء إلى مناطق إستهلالكه فيى

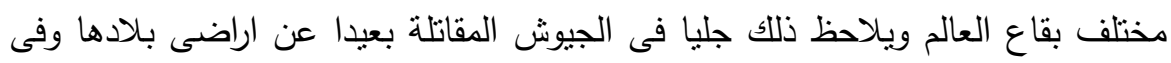

$$
\text { الرحلات الإستكثافية. }
$$

- الصناعات الغذائية مهمة فى إعداد غذائى قيمة غذائية متجانسة كما أن الأغذية المصنعة

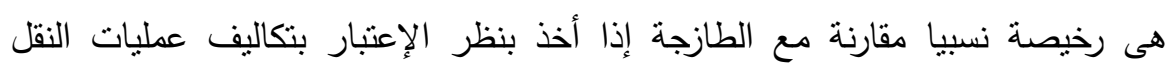

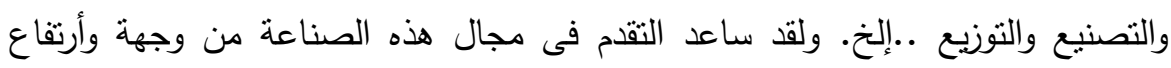
الاخل الإقتصادى للمواطنين فى كثير من بلدان العالم إلى الإبداع فى إنتاج أنواع عديدة

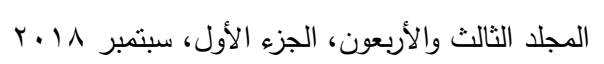


من الأغذية ففى أمريكا مثلا يتوفر فى الوقت الحاضر ما يزيد عن ... . . . نوع من أنواع الأغذية المصنعة.

- الصناعات الغذائية تأثثر مباشر على نتجيع صناعات أخرى ذات علاقة مباشرة معها كصناعة مواد التعبئة المختلفة من علب صفيح وعلب زجاجية وكذللك مواد التغليف وغيرها وصناعة المكائن الخاصة بالتصنيع والمواد الكيماوية الحافظة وفى تحسين وسائل الجنى

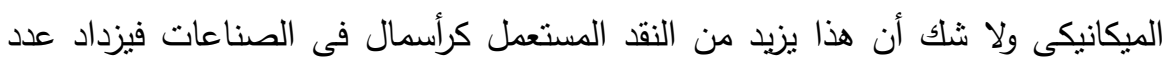
العمال المستخدمين حيث تقل البطالة وينتعش الإقتصاد القومى فى البلاد (حامد عبد الله

أثر الصناعات الغذائية على البيئة: وإن المخلفات الناتجة عن زيادة الانتاج الزراعي ومصانع الأغذية عديدة وكثيرة وسوف نحاول رصد وحصر أهم انواعها المؤثرة في البيئة محاولين تركيز الضوء بعض الثيء على الاثار الصحية لها ومحاولين ايجاد اسلم الطرق واسهلها

للتخلص منها وتجنب مخاطرها. من تلك المخلفات ما يأتى: مخلفات الانتاج الزراعي الحقل. مخلفات مصانع الخضر

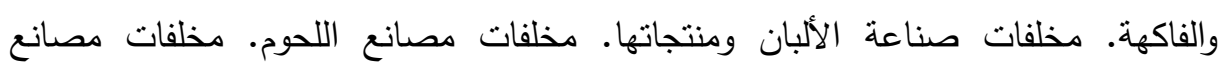
الأسماك. (مقالة بعنوان مخلفات الصناعات الغذائية وتأثيرها في البيئة وصحة الإنسان على التى http://www.alhadeeqa.com/vb/gardens/g2677/ الرابط: بعندان التلوث الناتج عن الصناعات الغذائية: يتسبب أختلاف الصناعات الغذائية وإختلاف عمليات التصنيع فى أن يجعل لكل نوع من هذه الصناعات مشاكله الخاصة به إلا أنه يمكن حصر بعض من هذه المشاكل فيما يلي:.

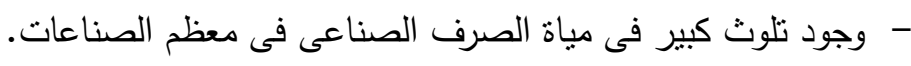
- إستهلاك كميات كبيرة من الماء والوقود وتولد كمية من السوائل المختلفة والمواد الصلبة معند عن العمليات الصناعية فى بعض الصناعات ومنها صناعة تكرير السكر .

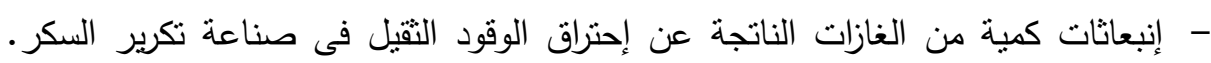

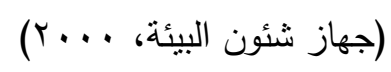




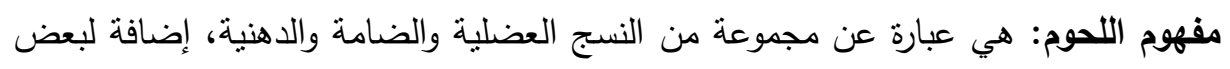

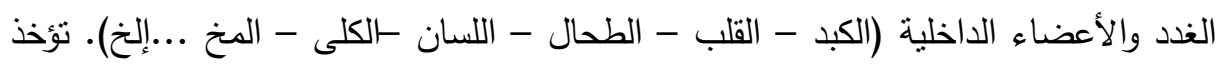
اللحوم من ذبائح الحيوانات والصالحة للاستهلاك شريطة خلوها من الآفات والأمراض، ومتفقة مع عادات وتقاليد المستهلكين. اللحوم الحماعِ: تؤخذ من ذبائح الحيوانات الثذيية المستأنسة مثل: الأبقار والأغنام والماعز

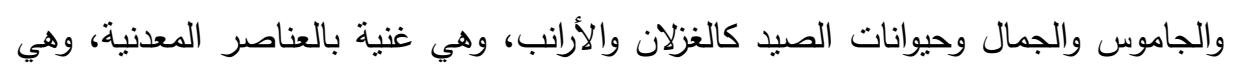
أيضاً ليست مصدراً للحديد فحسب بل وتنساعد على امتصاصه من المواد الغذائية الأخرى.

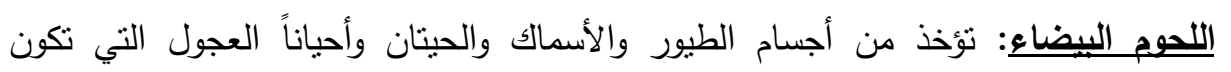
تغذيتها على الحليب بشكل أساسي، ويعد لحم الدجاج من اللحوم الطرية، وهو أسكل هضماً

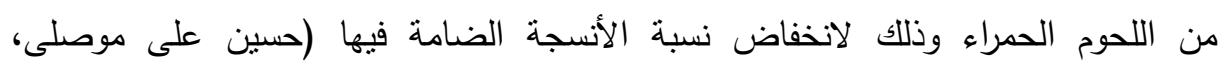

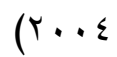
مخلفات صناعة اللحوم ومنتجاتها وتأثثراتها فحى البيئة: تشمل صناعة اللحوم ومنتجاتها العديد من المجازر (المسالخ) ومصانع اللحوم التى تختلف فى الحجم والمساحة من مصنع إلى آخر حيث تعتبر المخلفات الناتجة عن نلاك الصناعة منتابهة إلى حد كبير رغم إختلاف حجم المصنع أو المسلخ فالمياة الناتجة عن تلك المصانع التى تحمل الكثير من المخلفات

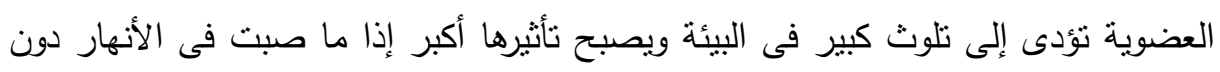

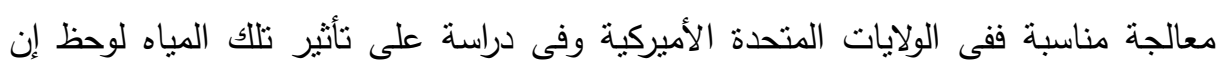

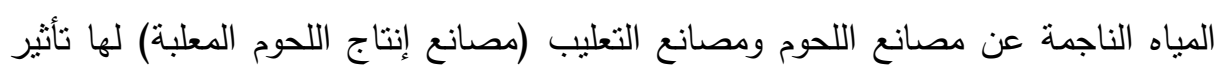

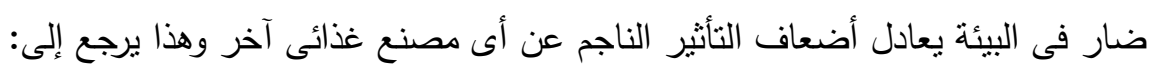

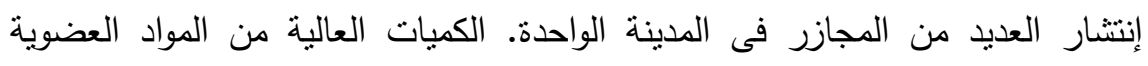
المحملة بها تلك المياه. التكلفة الإقتصادية العالية فى معالجة تلك المياه ويمكن تقسيم المخلفات الناتجة عن صناعة اللحوم ومنتجاتها إلى:

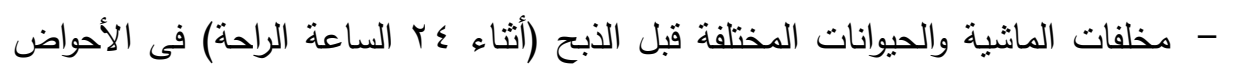

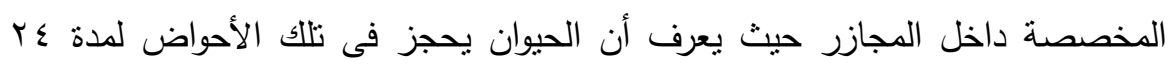


ساعة للراحة قبل عملية الذبح وذلك لإجراء الكثف الطبى عليه وتقدير مدى ملائمة لعملية الذبح - مخلفات المجازر بعد عمليات الذبح وإعداد اللحوم (متل الدماء الناتجة عن الذبح والسلخ ومخلفات الجهاز الهضمى (الأحشاء وغيرها) واللحوم غير الصالحة للإستهلاك الآدمى

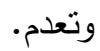

كل تللك المخلفات لها خاصية تعفنية ورائحة كريهة وإذا صرفت بدون معاملة إلى إى مصدر مائى كالأنهار فإنها تؤدى إلى نفاد وإستتفاد الأكسجين الذائب ومن ثم إلى إلحاق إضرار شديدة بالكائنات البحرية كما تؤدى إلى إنتشار الروائح الكريهة وترسبات طينية ووجود

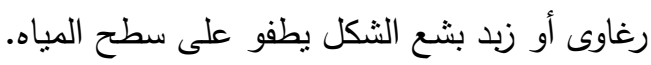
وتعتبر المصادر الآتية هى أهم المصادر المؤثرة فى المياة المستخدمة في المى المجازر : غسل الذبائح والأراضى والأوانى. الدم والدهون. المياه المستخدمة فى طهى أو تمليح اللحوم. مخلفات الحيوانات منل الجلود والكبد والكروش.... ألخ حيث إعداد كل ذللك يؤدى إلى تلوث المياة. (مقالة بعنوان مخلفات الصناعات الغذائية وتأثيرها في البيئة وصحة الإنسان على إلى http://www.alhadeeqa.com/vb/gardens/g2677/ الرابط: بعض الجواتب الإقتصادية لقطاع اللحوم ومنتجاتها: إقتصاديات إستهلاك اللحوم: تعتبر اللحوم من الأغذية ذات القيمة الغذائية العالية وتمنل جزءا" هاما" من غذاء الإنسان وتقضل إنصل بكثيرة لإستساغتها حيث تعتبر :

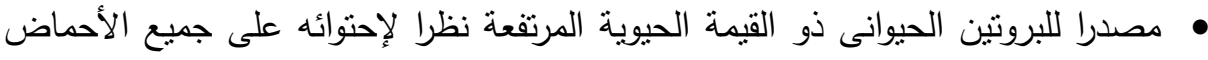
الأمينية الأساسية الضرورية للجسم بالنسب التى يحتاجها الإنسان.

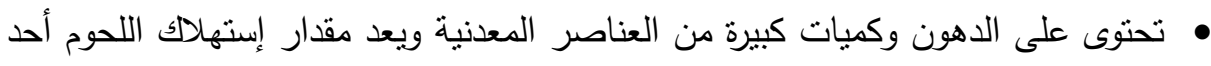

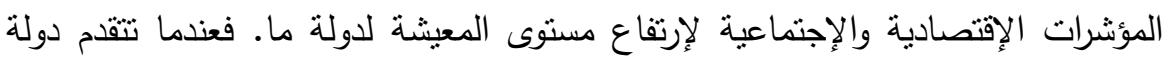

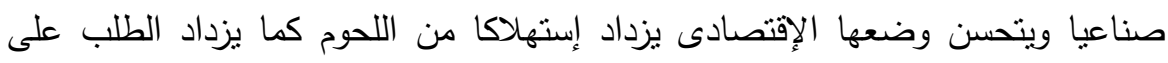

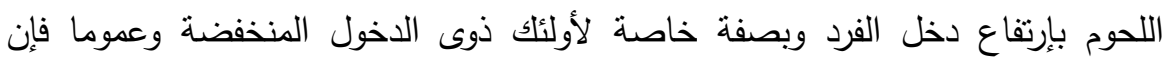


أسباب نقص البروتين بصفة عامة واللحوم الحمراء بصفة خاصة فى مصر تتلخص فى الآتى: - - نقص المراعى الخضراء الطبيعية فجمهورية مصر العربية من الدول الفقيرة فى المراعى.

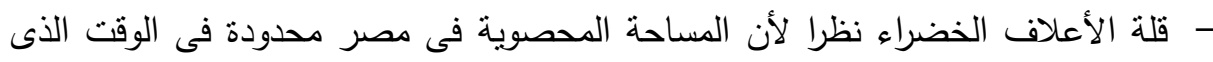
تتزايد فيه أعداد السكان بصورة مطردة مما يجعل تتافسيا بين إنتاج الحبوب لغذاء الإنسان

$$
\text { وإنتاج الأعلاف لتغذية الحيوان فى هذه المساحة. }
$$

- إرتفاع أسعار الاعلاف الجافة والمصنعة مما يجعل إستعمالها غير مجدى إقتصاديا

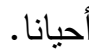

- قلة وجود سلالات لحم جيدة وصعوبة أقلمة السلالات المحسنة المستوردة مع ظروف البيئة

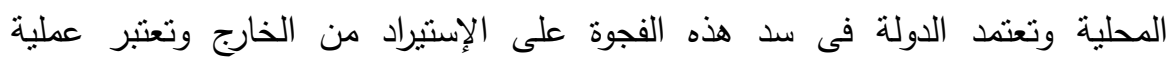

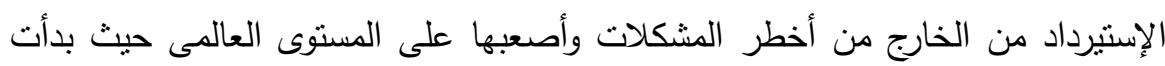

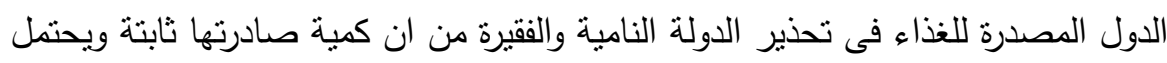

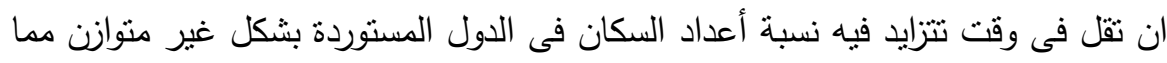

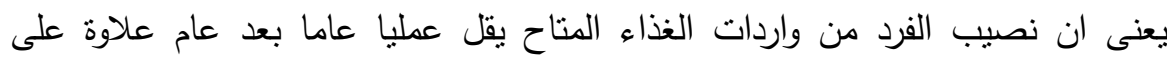
إرتفاع أسعار الغذاء على المستوى العالمى خاصة للمنتجات الحيوانية ونتشير الإحصاءات

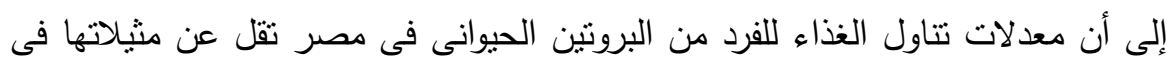

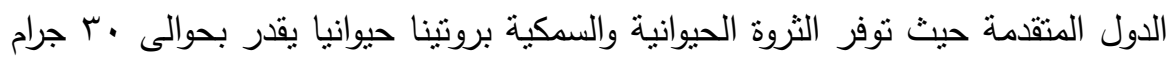

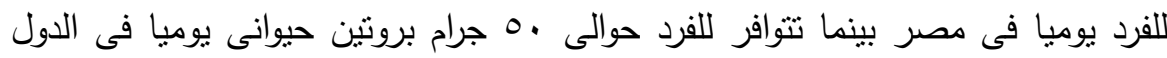

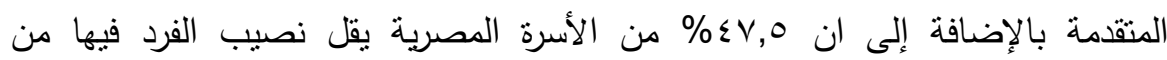
البروتين الحيوانى عن 0 اجرام بوميا. وقد حددت وزارة الزراعة فى مصر الأسس التالية للنهوض بأنيا. هالثروة الحيوانية:

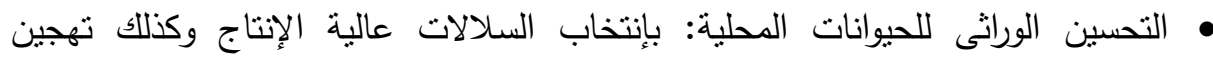
السلالات المحلية بسلالات أجنبية عالية الإنتاج. • التحسين البيئى: بتوفير الأعلاف الخضراء والعلائق الجافة وتوفير الرعاية الصحية الإنية للحيوانات ووقايتها من الطفيليات والأوبئة. 
ه العمل على الحد من الفاقد فى المجازر وأثناء النقل والتخزين: عن طريق إقامة مجازر آلية تذبح فيها الحيوانات بطريقة صحية ثم تعبأ وتخزن وتتقل بوسائل نقل مجهزة بالتبريد

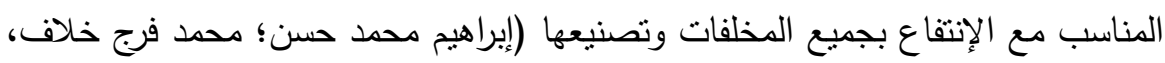

\section{إجباعاهت المهAه}

قامت الباحثة بجمع البيانات على CD من الجهاز المركزى للمحاسبات ووزارة الزراعة

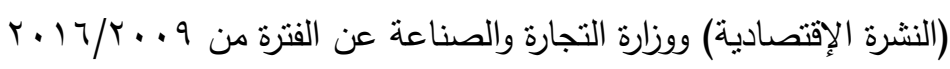

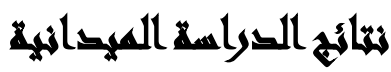

من خلال هذا الفصل عرضت الباحثة نتائج الدراسة الميدانية بدراسة بعنوان "تحليل

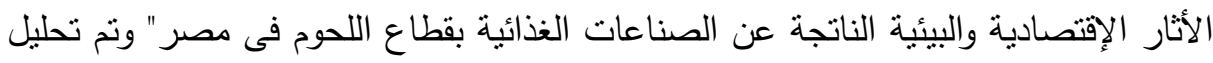
البيانات في ضوء فرض علاقة طردية بين الصناعات الغذائية والنمو الإقتصادى المصرى الإن.

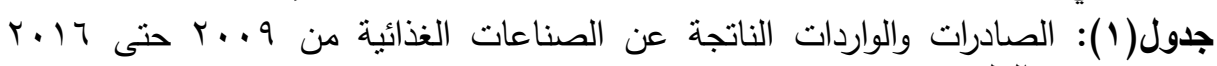

\begin{tabular}{|c|c|c|c|}
\hline فائض - عجز & الواردات & الصادرات & السنة \\
\hline T.T & E,r. & 1695. & $r \ldots q$ \\
\hline$r_{6} \cdot 10$ & $0.0 \mathrm{VT}$ & TGYYO & $r \cdot 1 \cdot$ \\
\hline$r .0 .1$ & $7, M 1 \leq$ & $Y_{6} \wedge .7$ & $r .11$ \\
\hline 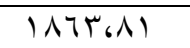 & 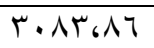 & IYr.6.0 & $r .1 r$ \\
\hline $1 Y 976 \leqslant 5$ & $r V \cdot \Lambda_{6} V T$ & IEITGK & $r .1 T$ \\
\hline $1 \leq 0161 \mathrm{~V}$ & $r \wedge 9 r .9 r$ & $1 \leq \leqslant Y_{6} \vee 0$ & $r \cdot 1 \varepsilon$ \\
\hline $1 \wedge Y \cdot 6 \wedge T$ & $M I \leq r, Y Y$ & IMYT,T4 & $r .10$ \\
\hline$\left|r \cdot V_{6} \lambda\right|$ & YYYY.9I & $1 \leq 1061$. & $r .17$ \\
\hline
\end{tabular}

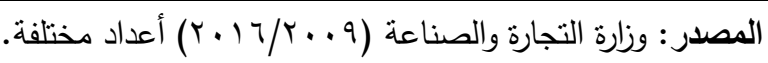

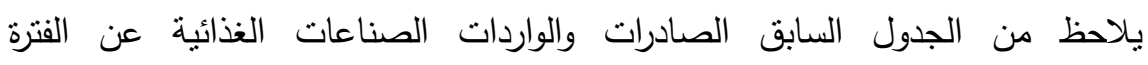

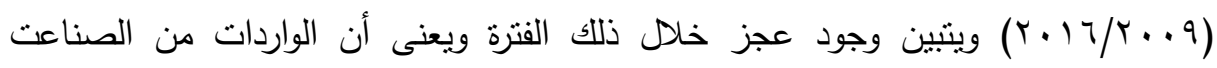

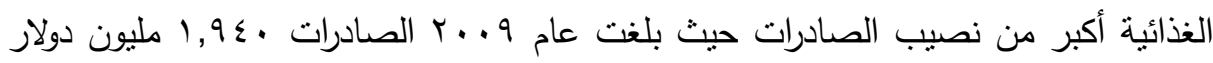

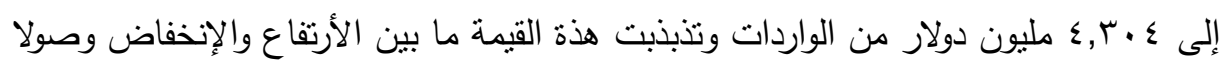




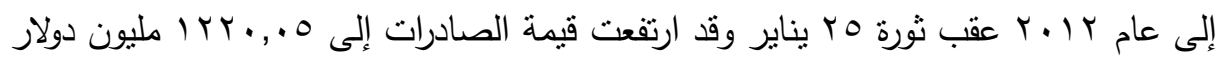

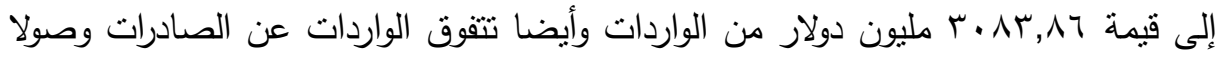

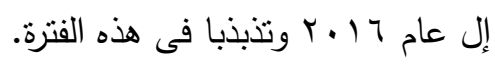

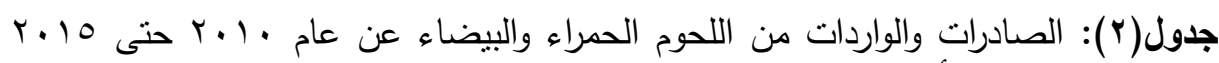
(القيمة ألف جنيه)

\begin{tabular}{|c|c|c|c|}
\hline فائض - عجز & الواردات & الصادرات & السنة \\
\hline $07 V \varepsilon \cdot \varepsilon \cdot-$ & OVITVAV & $\varepsilon r V \leqslant V$ & $r .1$. \\
\hline $07 . \leq 77 V-$ & $07 \leqslant 1919$ & $\varepsilon \varepsilon \sum Y O Y$ & r.11 \\
\hline$\Lambda \Sigma q \ldots r r-$ & $10.9 \ldots 1$ & $1 \wedge 9 \vee \wedge$ & $r .1 Y$ \\
\hline Arq० & NT.VTVO & $1 Y \mid V 7$ & $r .1 T$ \\
\hline $1 Y \ldots \leqslant 009-$ & IY. KMTYY & 19.77 & $Y, 1 \leq$ \\
\hline $10491 \cdot 10-$ & $10 \varepsilon \cdot 79 \mu r$ & 10911 & $\mathrm{r}, 10$ \\
\hline
\end{tabular}

المصدر: وزارة الزراعة واستصلاح الأراضى قطاع الثئون الإقتصادية (أعداد مختلفة).

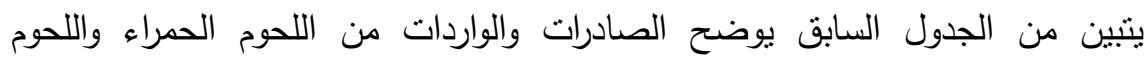

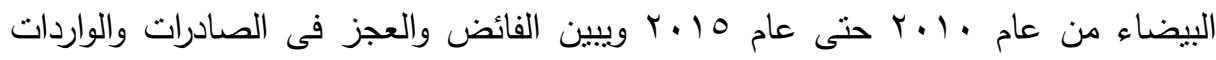

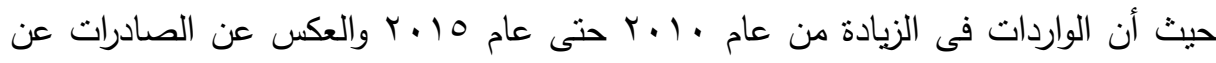
هذة الفترة وهذا يعنى الزيادة فى الطلب.

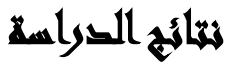

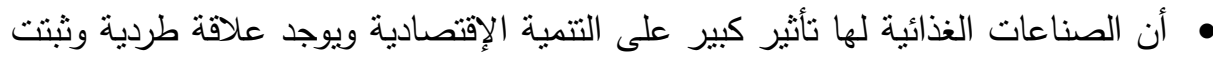
صحة هذا لذلك ضرورة دعم القطاع من الدولة بصورة مستمرة لرفع نسبة الصادرات لتعود على التتمية الإقتصادية بالإيجابية بصورة مستمرة. • ينتج عن مخلفات الصناعات الغذائية عن طريق دفنها أو حرقها أضرار كبيرة قد تضر بالئرة البيئة الداخلية والخارجية والتى تؤثز فى تلوث الماء وتلوث الهواء مما يحقق أضرار بالمجتمع. • إن تدوير مخلفات الصناعات الغذائية قد تعود بالنفع الإقتصادى على الدولة بزيادة الدخل القومى بإستغلال ذلك المخلفات فى إعادة تدويرها فى توفير أعلاف للحيوانات وتقليل الأنفاق فى الصرف على نقل هذه المخلفات إلى أماكن المخلفات ويمكن إستغلالها في لوفيز مكانها بالتكنولوجيا الحديثة. 
وضع خطة إقتصادية للعمل على زيادة اللحوم الحمراء والإكتفاء الذاتى من خلال الأنتاج

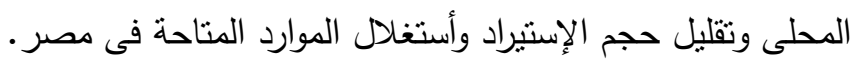

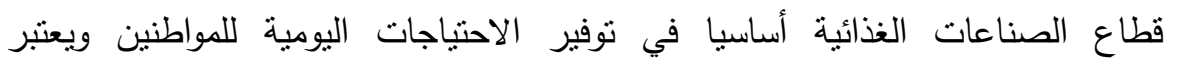
الصناعات الغذائية مصدرا رئيسيا فى توفير فرصة عمل وللقضاء على البطالة.

\section{المئوسيايت}

زيادة الدعم الموجة من الحكومة لقطاع الصناعات الغذائية النى تعتمد على سياسة الإنتاج

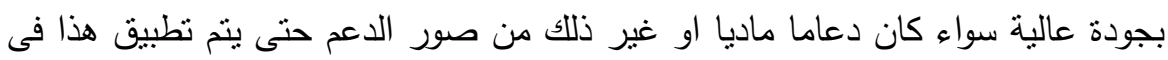

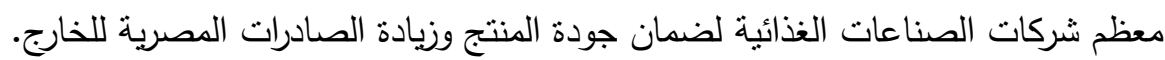
• تطبيق نظام الجودة والسلامة على المنتجات الغذائية والأهتمام بها والتصدير الخارجة. • العمل على خفض سعر بيع اللحوم ومنتجاتها بحيث تكون متاحة المستهلكين. • العمل على نطبيق الرقابة البيئية على قطاع اللحوم للحد من التلوث الناتج عن هذا القطاع. تحديث وتطوير المسالخ على كافة المدن وتتديد الرقابة على الذبح داخل أو خارج توعية المستهلك بطريقة حديثة ومبسطة حول مصادر التلوث الأغذية وكيفية الوقاية منه. قدرة قطاع الصناعات الغذائية فى مصر على التطور من خلال تفعيل برامج لتحديث

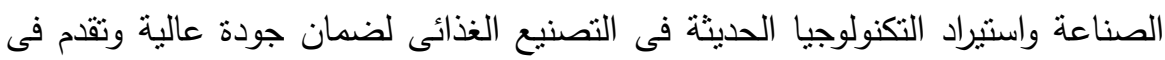
الأسواق الخارجية لزيادة الصادرات.

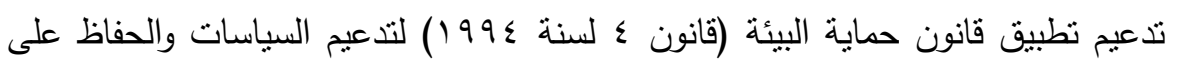
البيئة. • ضرورة تشجيع الدولة على الإستثمار فى التكنولوجيا الحديثة والنظيفة للإنتاج غير ضار للحفاظ بالبيئة. 


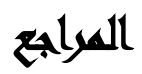

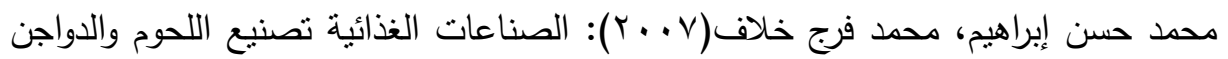

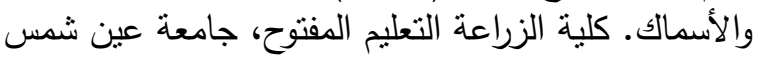

حامد عبداله جاسم(999 (1)): الصناعات الغذائية الجزء الأول، كلية الزراعة، جامعة بغداد.

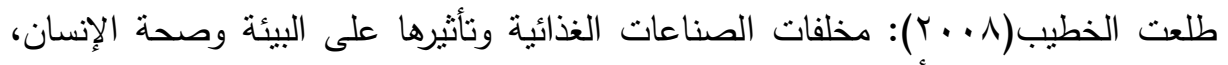
جامعة أسيوط

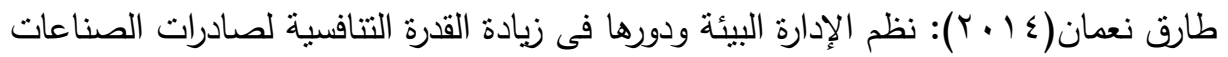
الغذائية المصرية. بحث دكتوراة بمعهد الدراسات والبحوث البيئية، جامعة عين

شمس

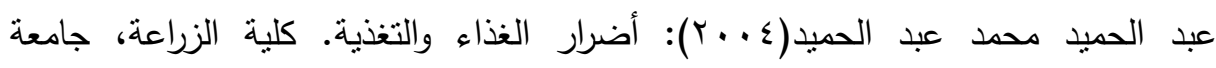
المنصورة

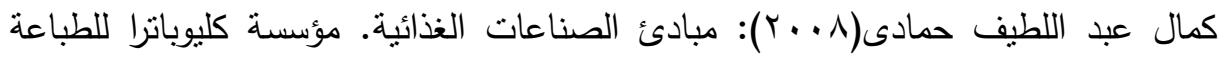
والنشر

محمد موافى(10 + ب): مقال بعنوان عوامل وراء تراجع نمو قطاع الصناعات الغذائية، إقتصاد

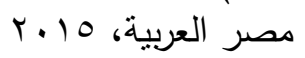

وزارة الصناعة والتجارة الهيئة العامة على الصادرات والواردات غرفة الصناعات الغذائية تقرير

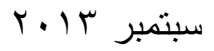




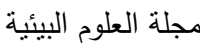

معهد الدراسات والبحوث البيئية - جامعة عين شمس لمس لئن

\title{
ANALYSIS OF THE ECONOMIC AND ENVIRONMENTAL IMPACTS RESULTING FROM FOOD INDUSTRY IN EGYPT
}

\author{
Abdel Monem, Zainab, L. ${ }^{(1)}$; Mandour, A. F. ${ }^{(2)}$ \\ and Abdel Aal, M. H. ${ }^{(2)}$
}

1) Institute of Environmental Studies and Research, Ain Shams University 2) Faculty of Commerce, Ain Shams University

\begin{abstract}
Food industries consider one of the significant basic pillars sectors in Egypt that deal with crucial topic inked to human beings' lives and their nutritional security. Food industries have developed recently in the last few year to occupy a fundamental position among the state's main resources and economics. This industry is characterized by producing outcome from agricultural production involving its two-fold divisions, the plant and animal. Despite the fact that each industry of these has common inputs similar in their general properties for giving products its specific qualifications, each has its own natural and chemical traits that contributes improving the citizens' nutritional balance, growing of areas, in addition to role as a resource of foreign currency by exportation to other countries.

This study discusses the economic and environmental impacts of food industries in meat sector. The analytical method is used. Using also the deductive approach that depends on collecting necessary data and information to be analyzed and extract results.

Results indicate that food industries in meat sector have a significant influence in economic development results in importation and exportations. It also has a significant impact on economic growth as there is a direct correlation between food industries and economic growth.Consequently, the state should consider and care of food industry sector for the purpose of raising efficiency of productive

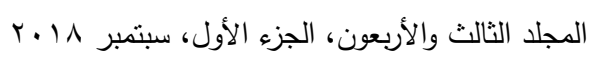


زينب لمعى عبد المنعم وآخرون

performance in companies, developing and promoting food industries in Egypt which is set in priorities of the up-to-date programs for being capable of competitive advantages in world markets. 